completely known aside from our knowledge of that of the comet. Every August, about the tenth day, we have an unusual number of meteors-a star-sprinkle, as it has been called. A comet whose period is about 125 years moves in the plane, and probably in a like orbit with these meteoroids.

So near the first of December we have had several star-showers-notably one in 1872 - and these meteoroids are travelling nearly in the orbit of Biela's comet. In April, too, some showers have occurred which are thought to have had something to do with a known comet.

Thus much as to the meteors of the star-showers. The sporadic meteors are with good reason presumed to be (and observed facts prove some of them to be) the outliers of a large number of meteoroid streams, and the leading problem of meteor-science to-day is to find these streams so faintly shown, and, if possible, the comets they belong to.

Come back with me to the November stream and its comet. The several bodies move along a common path not at all by reason of a present physical connection. They are too far apart, in general a thousand times too far apart, to act on each other so much that we can measure the effect. No; their connection has been in the past. They must have had some common history.

Looking now at the comets, we see that they have been apparently growing smaller at successive returns. Halley's comet was much brighter in its earlier than in its later approaches to the sun. Biela's comet has divided into two, if not more than two, principal parts, and seems to have entirely gone to pieces. It could not be found in 1872, when and where it ought to have been visible. Several comets have had double or multiple nuclei. In the year 1366 , in the week after the star-shower, a comet crossed the sky exactly in the track of the meteors. A second comet followed in the same path the week after. Both belonged no doubt to the November stream, and one of them may perhaps have been the comet of 1866 .

This stream of meteoroids is a long thin one. In miniature it would be perhaps a mile long to an inch in thickness. We have crossed the stream at many places along a length of a thousand millions of miles, sometimes in advance of, and sometimes behind, the comet, and all along this length have found fragments, sometimes few, sometimes many. This form of the stream suggests continuous action producing it. A brief violent action might give this form, but a slowly acting cause seems more natural.

Again, in the history of Biela's comet we have distinct evidence of continued action. The comet divided into two parts not long before 1845 , and yet in 1798 fragments of it were met with so far from the comet, that they must have left the comet long before, probably many centuries ago.

Thus are we led to say, first, that the periodic meteors of November, of August, of April, \&c., are caused by solid fragments of certain known or unknown comets coming into our air; secondly, that the sporadic meteors such as we can see any clear night are the like fragments of other comets; thirdly, that the large fireballs are only larger fragments of the same kind; and finally, that this stone, which was broken off from one of those large fragments in coming through the air, must once have been a part of a comet.

Here I should naturally close, yet I am sure that you will ask, How came the comet to break up? Perhaps the prior question would be, How came the comet together? In its history there is much that we cannot yet explain, much about which we can only speculate. Thus, how came this stone to have its curious interior structure? As a mineral it resembles more the deepest firerocks than it does the outer crust of our earth. It seems to have been formed in some large mass, possibly in one larger than any of our existing comets. Some facts show that the comets have almost surely come to us from the stellar spaces. Out somewhere in the cold of space a condensing mass furnished heat for the making of this stone. The surrounding atmosphere was unlike ours, since some of these minerals could hardly have been made in the presence of the oxygen of our air. Either in cooling, or by some catastrophe, the rocky mass may have broken to pieces, so as to enter the solar system, having little or no cohesion, like a mass of pebbles; or, it may have come and probably did come, a single solid stone. In either case, as it got near to the sun, new and strong forces acted on it. The same heat and repulsion that develops and drives off from a comet in one direction a tail, sometimes a hundred millions of miles long, may have cracked off and scattered in another direction solid fragments. One of these contained in it this stone, and it wandered in its own orbit about the sun, itself an infinitesimal comet, how many thousands or millions of years we know not, until three years ago it came crashing through the air to the earth in lowa. Thence this fragment came here to serve as a text to my discourse.

METEOROLOGICAL STATION ON BEN NEVIS

WE are glad to learn that the Scotch Meteorological Society's scheme of a station on Ben Nevis is evoking cordial support from those who have the administration of Government funds available for such objects. The London Meteorological Council, of which Prof. Henry Smith is chairman, has unanimously agreed to offer to the Scotch Society $100 l$. yearly towards the support of the station, provided a copy of the observations is sent regularly to London. This is at once testimony by the most competent judges to the importance of the scheme, and a proper encouragement to the Scotch Society to proceed in its spirited enterprise. We understand that to uphold the station and induce two competent observers to take it by turns to live on the top of the mountain with an assistant will cost about $300 l$. yearly. It is estimated that to purchase a full stock of instruments and erect a building for them and the observers a capital sum of $800 \%$. will be required. The Scotch Society has applied for a grant of $400 l$. towards this expenditure from the Committee appointed by Government to distribute $4,000 l$. annually to encourage scientific research. We believe the Committee has not yet met to consider the various claims which are, no doubt, as usual made on the funds.

\section{RESEARCH UNDER DIFFICULTIES}

THE following short preface to a very valuable account of the stages of development from the egg of one of the centipedes (Geophilus), no member of which group had been studied previously to this account, gives so convincing a picture of the enthusiasm for investigation which may animate the modern naturalist, that it is worthy of a place in NATURE for the encouragement of the "craft." Elias Metschnik off has during the past fifteen years worked more assiduously with the microscope at the observation of the minute details of embryology than any other student. To him we are indebted for our first accurate knowledge of this subject in the case of many important animal forms, e.g., sponges, various jelly-fishes, marine worms, the scorpion, and the book-scorpions, various insects, crustaceans, starfishes, and ascidians. One result has been the injury of his eyesight. In reading to-day his memoir on Geophilus, published in 1875 (Zeitschr. fiir wiss. Zoologie), it occurred to me that the following passage has more than technical interest:-

"After having for many years sought in vain for material suited for the investigation of the embryology of the centipedes, I chanced to obtain a quantity of the eggs of 